\title{
Optimum Utilization of Hybrid Energy Systems for SCOE Building
}

\author{
Pranali S. Thakare* and A.B. Kanase-Patil \\ †Mechanical Engineering Department, SCOE, Vadgaon, Savitribai Phule Pune University, Pune, Maharashtra, India \\ Accepted 15 June 2016, Available online 20 June 2016, Special Issue-5 (June 2016)
}

\begin{abstract}
Over the decades the consumption of conventional energy sources has grown leaps and bounds to cater the increasing energy demand better the living standards of the society. The increased consumption has at risk the limited reserves of the conventional energy sources raising the interest to look for an alternative resource for sustainable development. The increasing demand and need for a greener technology led to the development of energy used from renewable energy sources. The present work will be carried out to optimize the utilization of renewable energy at Sinhgad college of Engineering, Pune. The new extensively emerging solar/PV, wind energy being used with emphasis on biomass/biogas. Considering the limitations of this off-grid supply, a hybrid system being designed for optimum and effective utilization using Hybrid Optimization Model for Electrical Renewable (HOMER), the micro power optimization model simplifying the task of evaluating design of both off-grid and grid connected power systems making the overall system easier. MATLAB code will be developed and used for comparative analysis with HOMER. The optimized solution is recommended for the campus which serves the purpose of Green Campus initiative.
\end{abstract}

Keywords: Optimization, HOMER, Hybrid energy system, MATLAB.

\section{Introduction}

The remote rural areas of the world are geographically apart, sparsely populated with very low power demand and not accessible to utility grid. In developing countries like India, large population in remote rural areas do not have the access to the grid power and is the main hurdle in the improvement of living standards of the people. In India, under the Rural Electrification Act 2003, provisions have been made to electrify such areas by renewable sources. Nowadays, the optimizing utilization of renewable energy sources diminish the usage of endangered fossil energy is a brilliant idea. The electricity supply of power plants using renewable energy sources in standalone installed is hard to grow due to unreliable and expensive. It relates to the fluctuation of renewable energy availability (e.g. solar, wind, biogas etc.) and its amount rely on the place, time, climate and weather. In the meantime, the area employing the network utilities (on-grid area), the energy cost of power plants using renewable energy sources in stand-alone is more costly rather than the electricity selling price of the grid system. This condition is occurred by the government subsidy of electricity selling price in the grid system. The effective work maintaining the power supply reliability of renewable energy sources relative to the combination of multiple power plants in different energy sources

*Corresponding author: Pranali S. Thakare namely is hybrid power systems. The hybrid system consist of the power plant using renewable energy sources, such as photovoltaic (PV), micro hydro (MHP), wind, biomass, and others, employing battery storage. In this investigation the possibility to develop the simple micro-grid model optimizing the utilization of local renewable energy for on-grid area is analyzes. The optimization is carried using HOMER software related to the size and type of energy conversion technologies used by local renewable energy sources (PV, Wind and Biogas). In addition, the micro-grid model is analyzed using MATLAB software to observe its performance.

\section{Literature Review}

Sen et al. conducted a case study of the best hybrid technology combination for electricity generation from a mix of renewable energy resources. This study preowned the HOMER software package developed by NREL for designing micro-power systems but complete it by undertaking pre- and post-HOMER analysis. A hybrid system with small hydro power proves to be the cheapest option compared to other RETs.

Anaerobic Digestion (AD) with biogas combined heat and power (CHP), photovoltaic and storage elements were used as a resource to fulfill the electrical demand by Castellanos et al. The simple energy system with a big PV generator required large battery storage systems and thus more investment and higher energy 
cost. This research has involved the selection of two $\mathrm{PV}$, four $\mathrm{AD}$ and a combined $\mathrm{AD}$ \& $\mathrm{PV}$ scenario using micro-grid modeling software- HOMER. . The biogas CHP was able to meet the electrical load peaks and variations and generated $61 \%$ of the total electricity in the optimized system, whiles the photovoltaic fulfill the daytime load and allowed the charging of the battery which was used to meet base load at night. The integrated renewable energy system had a lower capital and electricity cost over the life of the project was lower at \$0.289 KWh-1.

Hossan et al. presented hybrid system consists of photovoltaic array, small hydro plant with battery and diesel generator for backing up. Firstly using HOMER, operational scheme has been organized and after that dynamic model has been derived in MATLAB simu link with the required formulation. Cost efficiency (0.274) of $\mathrm{PV} /$ hydro/battery/diesel system is lower than hydro/generator/battery (0.276) system with a distant comparison in renewable fraction.

Green power technologies that are mainly using environment friendly sources like solar energy, wind energy, biomass, considering the stand alone system has been presented by Bansal et al. Best combination based on minimum cost of energy criteria has been suggested. The least cost of energy was found to be Rs. 12.462 per KWh. The model developed through HOMER basically is based on the assumption of values of resources which is not realistic. On the contrary, the design needs a proper and realistic estimation of these values. It is, therefore, concluded that there is a need to establish procedure to estimate the values using some statistical techniques.

Kanase-Patil et al. discussed the concept of integrated renewable energy systems (IRES) for energizing the remote rural areas of developing countries by using sources like hydro, biomass, biogas, solar and wind. The paper represented the comparison between the individual large power plant, the hybrid system and integrated renewable energy systems. The demand of a village/ block/ district including cooking and heating energy needs through IRES has been expected to be the best option among all three processes of rural electrification. This paper reviewed the energy resources, optimization methods and sizing parameters for IRES.

The present work has been carried out to optimize the utilization of renewable energy sources with emphasis on micro hydropower by Kanase-Patil et al. Using HOMER for optimization and the biomass and hydropower were the main resources for this tool. The sensitivity of cost of biomass was calculated and the cost of energy found to be Rs 4.9/KW for zero biomass prices. An optimized model consisting of MHP, SPV and BES have been constructed and optimized using HOMER software 2.67-beta version. The results indicate that model can consider biomass as the major resource up to cost of Rs. $8.75 / \mathrm{kg}$. Varshney et al. analyzed the hybrid energy system consists of PV, micro hydro, biomass, diesel and battery to fulfill the requirement of rural area. It also performed sensitivity analysis to see the impact of solar insolation, PV investment cost, wind speed, and diesel fuel price on the optimum result. Sizing and optimization of different component has been done using HOMER to minimize the cost and enhance reliability of system. It was seen that SPV, MH, biomass with battery, inverter, and diesel generator have the lowest total NPC of $\$ 1,453,997$ and COE $\$ 0.19 /$ KWh. LINDO software was used for sizing purpose.

Rozlan et al. identified the system life cycle cost or total net present cost, of the optimal hybrid energy system, where this analysis optimized in HOMER. The integration of fuel cell system into PV/ wind/ battery system not only used for backup power via hydrogen conversion but also can reduce the battery storage requirement by use of hydrogen tank. It helped the designer to determine the optimum system of photovoltaic, biomass, diesel generator, wind turbine, fuel cell, hydroelectric, batteries, electrolyser, flywheels by entering several numbers of data into the software. Negi et al. this paper was a review of hybrid renewable energy power generation systems focusing on energy sustainability. Ajao et al. analyzed the cost benefit of a solar-wind power hybrid system. It determined the payback period when compared to cost per kilowatt of utility power supply. In solar photovoltaic applications, the solar radiation is converted directly into electricity. The most common method of doing this was by the use of silicon solar cells. HOMER's optimization and sensitivity analysis algorithms make it easier to evaluate the many possible system configurations. Total net present cost (NPC) is $\$ 4251$ and cost of energy (COE) is $1.74 \$ / \mathrm{KWh}$.

\section{Proposed Work / Methodology Proposed}

\section{Selection of Site and Data Collection:}

SCOE Building is selected as the site for electrification. The necessary data for renewable systems will be collected and analyzed from IITM, Pune \& HOMER with the help of NASA satellite.

\section{Resource Finding and Potential Estimation:}

The analyzed data will become helpful to find out the resources that can be economically feasible to harness electrical energy. The potential finding of the renewable resources available in that local area and finding out available sizes in market.

\section{Cost of energy by HOMER}

For the above selected data's the cost of energy was estimated by only PV component. Then proceeded by only wind \& only biogas and followed by the combination of two \& three component.

\section{Optimization by HOMER and MATLAB software}

In Hybrid Optimization Model Electrification Renewable (HOMER), an algorithm is used in 
optimization process and sensitivity analysis to simplify the evaluation of the feasible system configuration. HOMER, the micro power optimization model, simplifies the task of evaluating designs of both off-grid and grid-connected power systems for a variety of applications. MATLAB code will be developed using optimization method and used for comparative analysis with HOMER.

\section{Results and Conclusion}

The optimum results and contribution of each renewable to get optimum and cost effective power will be summarized in this section.

\section{Objective}

HOMER provides non-realistic values so that data cannot be used directly. Various nonconventional sources are available to satisfy same load but there is no proper procedure available which help to choose one of these sources or combinations of them to minimize the cost. There is need of developing some analytical way to find suitable option like solar and wind or biogas and wind etc. Use of such mathematical and software approach will help to pre estimate the plant cost and possible problems can be overcome.

\section{HOMER Analysis}

The intended hybrid energy system is incorporated of renewable sources like PV, wind and biogas. A power converter has been used for changing the source bus from DC to AC. This integrated system is totally designed for off-grid electrification. For operational measurement a software HOMER is assigned. This software is used for cost optimizing with different sensitivity variables. Here, the varying subjects are load, global solar irradiation, wind speed etc. Model organization of HOMER has been addressed in Fig. 1.

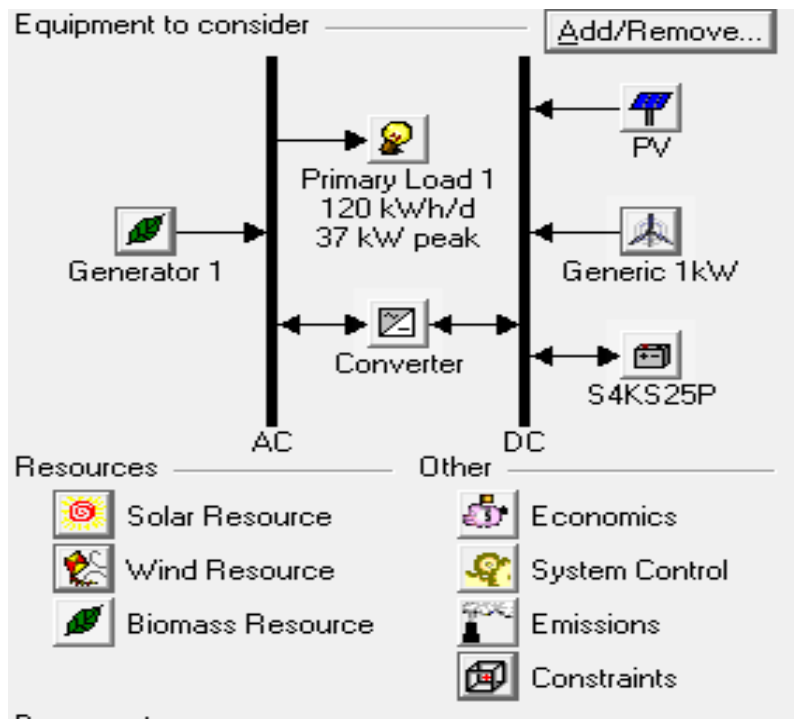

Fig. 1 Hybrid Energy System

\subsection{Load Profile}

Cited place for this project is SCOE building, vadgaon budruk, Pune. The latitude and longitude of the place is $18^{\circ} 32^{\prime} \mathrm{N}$ and $73^{\circ} 50^{\prime} \mathrm{E}$ respectively. The load profile is acquired based on basic demands of utilities like light, fan, workshop machines and laboratory equipment. Load is varied with seasonal and monthly consumption depending on climate. Total consumption is $120 \mathrm{KWh} / \mathrm{d}$ whereas the peak is $37 \mathrm{KW}$. One load profile is selected for month of January to May, second one for June to September and last one for October to December as shown in following fig. 2 .

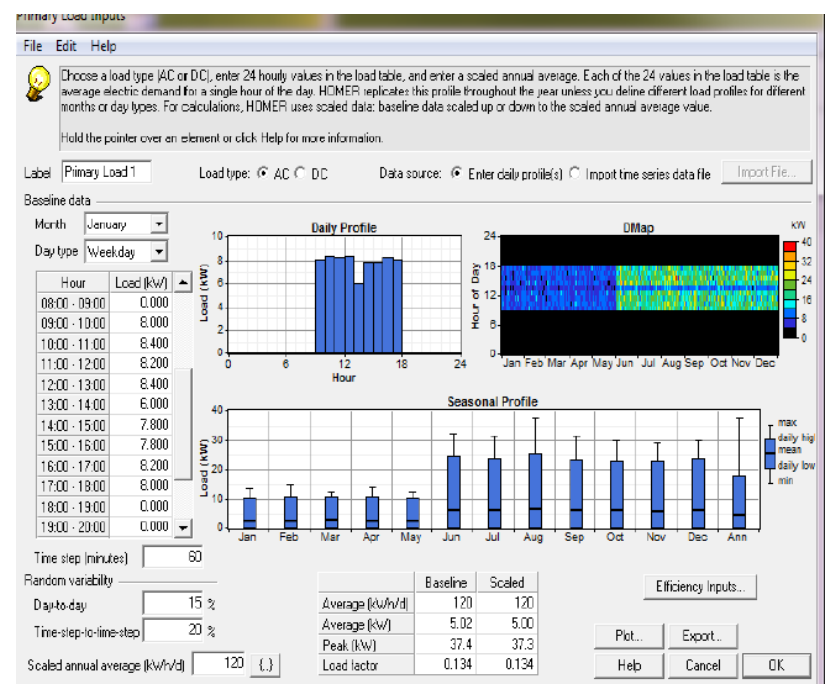

Fig. 2 Monthly load profile for January to May

\subsection{Cost of Energy finding by HOMER}

For the above selected data's the cost of energy was estimated by only PV component. Then proceeded by wind and biogas followed by the combination of two and three component i.e. wind and PV and wind, PV and biogas.

1. When only PV component selected then cost of energy is obtained by HOMER as shown in following fig. 3.

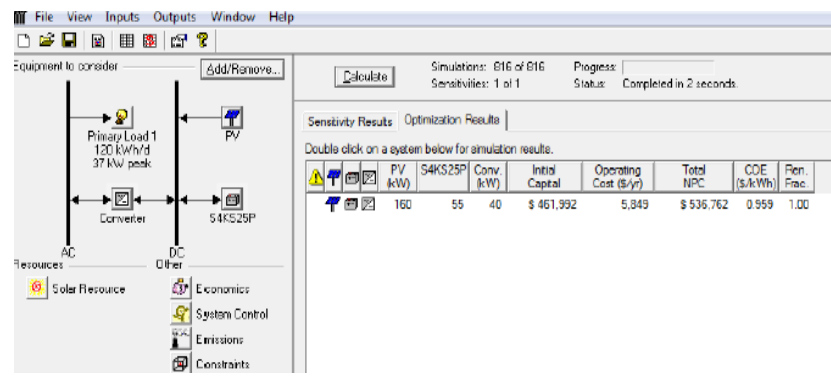

Fig. 3 Optimization results obtained from PV only

2. When only wind component selected then cost of energy is obtained by HOMER as shown in following fig. 4. 


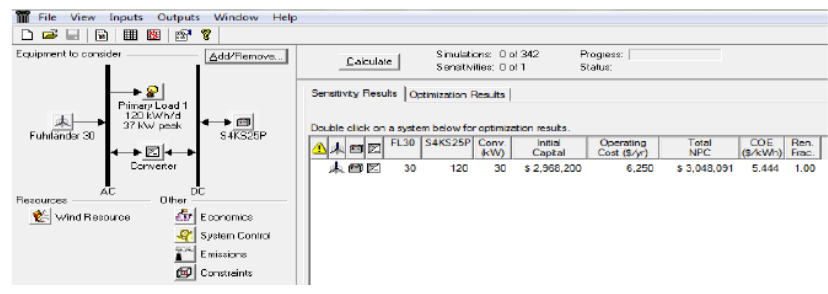

Fig. 4 Optimization results obtained by wind only

3. When PV and wind component selected then cost of energy obtained by HOMER is shown by following fig. 5 .

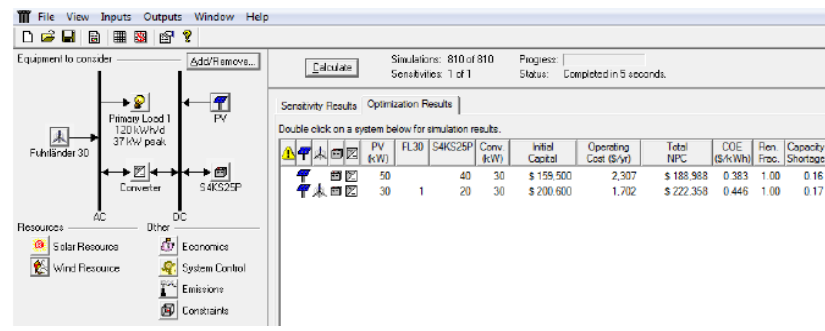

Fig. 5 Optimization results obtained by PV and wind Data Reduction

\section{Mathematical Model for Renewable Energy Sources}

The expressions for the electrical power output of wind energy system, micro hydro power system, solar photovoltaic system, biomass gasifier system and biogas system are represented below.

\subsection{Mathematical model for wind energy system}

$f(v, k, c)=(k \mid c)(v \mid c) k-1 \exp [-(v \mid c) k]$

where $f(V, k, c)$ is the probability of wind speed $(V), c$ is the scale parameter, $\mathrm{k}$ is the shape parameter and $\mathrm{V} \geq 0$, $\mathrm{k}>1, \mathrm{c}>0$.

The output of wind energy system depends on its rated power (Pr) of wind turbine, cut-in speed, cut-out speed and rated speed. Mathematically, electrical power output of wind turbine $\left(\mathrm{P}_{\mathrm{WT}}\right)$ is calculated as.

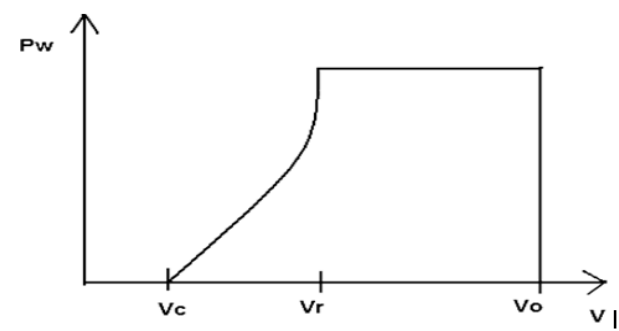

Fig. 6 Wind turbine characteristics.

\subsection{Mathematical model for solar photovoltaic system}

The input to solar photovoltaic (SPV) system is solar radiation. SPV panels are inclined at an angle equal to the latitude of the selected area to increase the amount of solar radiation received on SPV surface. The electrical power output of inclined SPV system mainly relies on amount of beam radiation and diffuse radiation, fallen on SPV surface. Total hourly solar radiation on a fixed inclined surface (HT) can be calculated as

$H_{T}=H_{b} R_{b}+\left(H_{b}+H_{d}\right) R_{r}$

$\mathrm{R}$ where $\mathrm{H}_{\mathrm{T}}$ is in $\mathrm{kWh} / \mathrm{m} 2, \mathrm{H}_{\mathrm{b}}$ is the beam part of solar radiation $(\mathrm{kWh} / \mathrm{m} 2), \mathrm{H}_{\mathrm{d}}$ is diffused part of solar radiation $(\mathrm{kWh} / \mathrm{m} 2), \mathrm{R}_{\mathrm{b}}$ is tilt factors for beam radiation, $\mathrm{Rd}$ is tilt factors for diffused radiation and $\mathrm{Rr}$ is the tilt factor for reflected part of solar radiations. Hourly power output of SPV system (Pspvs) is calculated as

$P_{\text {spvs }}=\eta H_{T} A$

where $\eta$ is the conversion efficiency of SPV system, A is the surface areas of SPV system. Annual energy output of SPV system is estimated as

$E S P V S=\sum(i=1)^{\wedge} 8760 P(S P V S)(i)$

\subsection{Mathematical model for biogas system}

Biogas is produced from animal manure and human sewage. In stand-alone mode, biogas and diesel are mixed in the ratio of 80:20 to run the diesel engine that in turn rotates the coupled alternator .In remote areas, biogas is used to fulfill the cooking energy needs of villages household and thereafter, if any surplus biogas is available that can be used for electricity generation. The hourly power output of biogas based system relies on biogas generation per day and operating hours of alternator in a day. The mathematical model for biogas based power generation system is represented as follows:

$\mathrm{P}_{\mathrm{BGGS}}=\frac{\text { total biogas generated }\left(\frac{\mathrm{m}^{3}}{\text { day }}\right) \times C V_{B G} \times \eta_{B G G S}}{860 \times \text { opearating hours } / \text { day }}$

\section{Results and Discussion}

1. When only PV component selected then cost of energy obtained by HOMER is $0.959 \$ / \mathrm{KWh}$.

2 . When only wind component selected then cost of energy obtained by HOMER is 5.44\$/KWh.

3. For combination of $\mathrm{PV}$ and wind cost of energy obtained by HOMER is $0.446 \$ / \mathrm{KWh}$.

4. For combination of $\mathrm{PV}$, wind and biogas cost of energy obtained by HOMER is $0.293 \$ / \mathrm{KWh}$.

\section{Conclusions}

Hybrid energy system consists of PV/ Wind/Biogas is chosen in this project work. Load required at given site is calculated, then solar resource data and wind data calculated from respective NASA surface meteorology website. Cost of energy was estimated by PV, wind and 
diesel generator using biogas i.e. firstly only by PV, then only by wind, then combination of wind and biogas and last combination of PV, wind and biogas. Hence the most optimal solution and less cost of energy is find out by selecting three energy resources namely $\mathrm{PV}$, wind and biogas.

\section{References}

Sen R., Bhattacharyya S.C.,(2014) Off-grid electricity generation with renewable energy technologies in India: an application of HOMER. Renewable Energy 62, 388-398.

Castellanos J.G, Walker M., Poggio D., Pourkashanian M., Nimmo W.(2015) Modelling an off-grid integrated renewable energy system for rural electrification in India using photovoltaics and anaerobic digestion. Renewable Energy 74, 390-398.

Hossan M.S., Hossain M. M, Reazul Haque A.R.N.M.,(2011) Optimization and modeling of a hybrid energy system for off-grid electrification.

Bansal M., Khatod D.K and Saini R.P., Modeling and optimization of integrated renewable energy system for rural site. (2014) International Conference on Reliability, Optimization and Information Technology-ICROIT 2014, India,
Kanase-Patil A.B., Saini R.P. and Sharma M.P.,(2007) Development of integrated renewable energy systems for electrification of rural remote areas. All India Seminar's on Energy, Environment \&Economics. 3-4

Kanase-Patil A.B., Saini R.P. and Sharma M.P.,(2008) Optimum utilization of renewable energy sources in a remote area. International Conference on Advances in Mechanical Engineering, S.V.National Institute of Technology, Surat-395 007, Gujarat, India.

Varshney N., Sharma M.P., Khatod D.K.,(2013) Sizing of hybrid energy system using HOMER. International Journal of Emerging Technology and Advanced Engineering. ISSN 2250-2459, Vol.3, No.6.

Rozlan M.B., Zobaa A. F., Abdel Aleem S.H.E.,(2014) Integration of standalone hybrid renewable energy systems optimisation using HOMER. International Review of Electrical Engineering (I.R.E.E), Vol.20.No.10. Negi S., Mathew L., Hybrid renewable energy system: a review. International Journal of Electronic and Electrical Engineering, ISSN 0974-2174, Vol.7, No.5.

Ajao K. R., Oladosu O.A., Popoola 0.T.,(2011) Using HOMER power optimization software for cost benefit analysis of hybrid-solar power generation relative to utility cost in Nigeria. IJRRAS 7. 